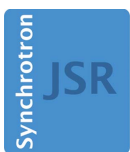

JOURNAL OF SYNCHROTRON RADIATION

ISSN 1600-5775

Received 2 September 2020

Accepted 6 March 2021

Edited by M. Yabashi, RIKEN SPring-8 Center, Japan

Keywords: Hard X-ray Nanoprobe; multimodal techniques; nano-XRD; nano-XRF; nano-

XANES; ptychography; spectro-microscopy.



\section{The Hard X-ray Nanoprobe beamline at Diamond Light Source}

\author{
Paul D. Quinn,* Lucia Alianelli, Miguel Gomez-Gonzalez, David Mahoney, \\ Fernando Cacho-Nerin, Andrew Peach and Julia E. Parker
}

Diamond Light Source, Harwell Science and Innovation Campus, Didcot, Oxfordshire OX11 ODE, United Kingdom.
*Correspondence e-mail: paul.quinn@diamond.ac.uk

The Hard X-ray Nanoprobe beamline, I14, at Diamond Light Source is a new facility for nanoscale microscopy. The beamline was designed with an emphasis on multi-modal analysis, providing elemental mapping, speciation mapping by XANES, structural phase mapping using nano-XRD and imaging through differential phase contrast and ptychography. The $185 \mathrm{~m}$-long beamline operates over a $5 \mathrm{keV}$ to $23 \mathrm{keV}$ energy range providing a $\leq 50 \mathrm{~nm}$ beam size for routine user experiments and a flexible scanning system allowing fast acquisition. The beamline achieves robust and stable operation by imaging the source in the vertical direction and implementing horizontally deflecting primary optics and an overfilled secondary source in the horizontal direction. This paper describes the design considerations, optical layout, aspects of the hardware engineering and scanning system in operation as well as some examples illustrating the beamline performance.

\section{Introduction}

Probing heterogeneous complex systems with a focused X-ray beam to measure local variations in composition, structure and morphology has been shown to be a powerful tool in diverse scientific areas including life science (Hémonnot \& Köster, 2017), cultural heritage (Cotte et al., 2018) and materials science (Johannes et al., 2017; Yu et al., 2018).

Recent years have seen rapid advances in the field of soft and hard X-ray microscopy, driven by the emergence of ultrabrilliant synchrotron sources (Tavares et al., 2014; Liu et al., 2014), advances in instrumentation (Holler et al., 2018; Schroer et al., 2017; Deng et al., 2019; Nazaretski et al., 2014) and new imaging methodologies (Deng et al., 2018; Yu et al., 2018). Hard X-rays in particular have benefited from significant advances in hard X-ray focusing optics using either reflective (Yamauchi et al., 2011), refractive (Seiboth et al., 2017; Patommel et al., 2017), diffractive (Huang et al., 2013; Suzuki et al., 2010; Mimura et al., 2010) and waveguide (Krüger et al., 2012) schemes to achieve beam sizes from $7 \mathrm{~nm}$ to $50 \mathrm{~nm}$.

These advances, coupled with the scientific demand for higher spatial resolution, have led to the construction of a number of hard X-ray nanoprobes at synchrotrons worldwide providing a broad range of techniques and beam-sizes (Chang et al., 2013; Suzuki et al., 2013; Nazaretski et al., 2017; Winarski et al., 2012; Martínez-Criado et al., 2016; Chen et al., 2014; Somogyi et al., 2015; Schroer et al., 2010; Johansson et al., 2013; Tolentino et al., 2017).

The science drivers for each beamline play a large part in the choice of focusing optic and optical layout, which in turn 
influences the working distance, beam size, energy range and chromaticity. Broadly speaking, multilayer Laue lenses or multilayer Kirkpatrick-Baez mirrors (KBs) can offer the highest spatial resolutions [currently $<10-20 \mathrm{~nm}$ (Huang et al., 2013)] but are primarily fixed-energy optics. Hard X-ray zone plates can typically offer resolutions down to $10 \mathrm{~nm}$ (Mohacsi et al., 2017) with a broader energy range, but with a need to adjust for energy-dependent focal lengths and generally reduced performance at higher energies. Reflective KB mirrors are achromatic, which makes them the most flexible and most suitable to spectroscopic studies and broad-energy operation; however, with a $40-50 \mathrm{~nm}$ beam size they offer comparatively lower spatial resolution. The science case for the Hard X-ray Nanoprobe, I14, at Diamond Light Source (DLS) is centred on spectro-microscopy and in situ operation in a broad range of areas including energy and battery materials, zircalloy cladding from the nuclear industry or radionuclides in environmental cells. In order to meet this demand, the nanoprobe uses a reflective $\mathrm{KB}$ system which operates over a $5 \mathrm{keV}$ to $23 \mathrm{keV}$ energy range and yields a nominal $\leq 50 \mathrm{~nm}$ beam (at $12 \mathrm{keV}$ ) for multi-modal analysis. The beamline provides spatial mapping of elemental composition by X-ray fluorescence (XRF), speciation by X-ray absorption near-edge spectroscopy (XANES spectro-microscopy), structural phase by nano-X-ray diffraction (nano$\mathrm{XRD}$ ), and phase or electron density through differential phase contrast (DPC) and ptychography, but with a particular emphasis on spectro-microscopy. In this paper, we report on the overall design, operational characteristics and key examples of operational performance.

\section{Beamline optical design}

The beamline design must sufficiently de-magnify the source while accounting for achievable levels of mechanical stability, allow enough working distance to meet the experimental requirements, provide a coherent beam for diffraction-limited focusing and coherent imaging applications, and be robust to energy changes during operation.

Nano- and micro-focusing optical arrangements can be single stage, in which the source is focused by the nanofocusing optic directly; two-stage, in which the source is focused to an intermediate aperture, acting as a source for the focusing optic; or a combination of the two schemes. The single-stage schemes offer minimal loss of coherence due to imperfect beamline optics, whereas two-stage schemes offer greater control over flux, coherence length and focused spot size (De Jonge et al., 2014). In practice, the source size at third-generation synchrotrons makes the two-stage solution unavoidable in the horizontal direction but allows some choice in the vertical direction, albeit with an impact on the overall beamline length.

The Nanoprobe at DLS is based on an astigmatic scheme using a combination of single and two-stage focusing. The beamline source is a U23 in vacuum undulator. The optics design considered the heatload from a $17.6 \mathrm{~mm}$-period cryogenic permanent magnet undulator which is currently under construction as part of a development program at DLS. Achieving a high-stability beam with $5 \%$ or $10 \%$ source size movement, with typical source sizes of $\sigma_{\mathrm{v}}=3 \mu \mathrm{m}$ and $\sigma_{\mathrm{h}}=$ $125 \mu \mathrm{m}$ in the vertical and horizontal, respectively, is significantly easier if the movement is in the horizontal direction. The beamline uses all-horizontal optics for beam conditioning prior to nano-focusing, exploiting the improved mechanical stability and the more manageable mechanical tolerances afforded by this geometry (Fig. 1).

Vertically, the source is unmodified and imaged directly by the vertically focusing KB mirror, which is located $185 \mathrm{~m}$ from the source. Horizontally, the beam is directed onto slits $52 \mathrm{~m}$ from the source, to form a secondary source aperture which is imaged by the horizontal mirror of the KB nano-focusing optic.

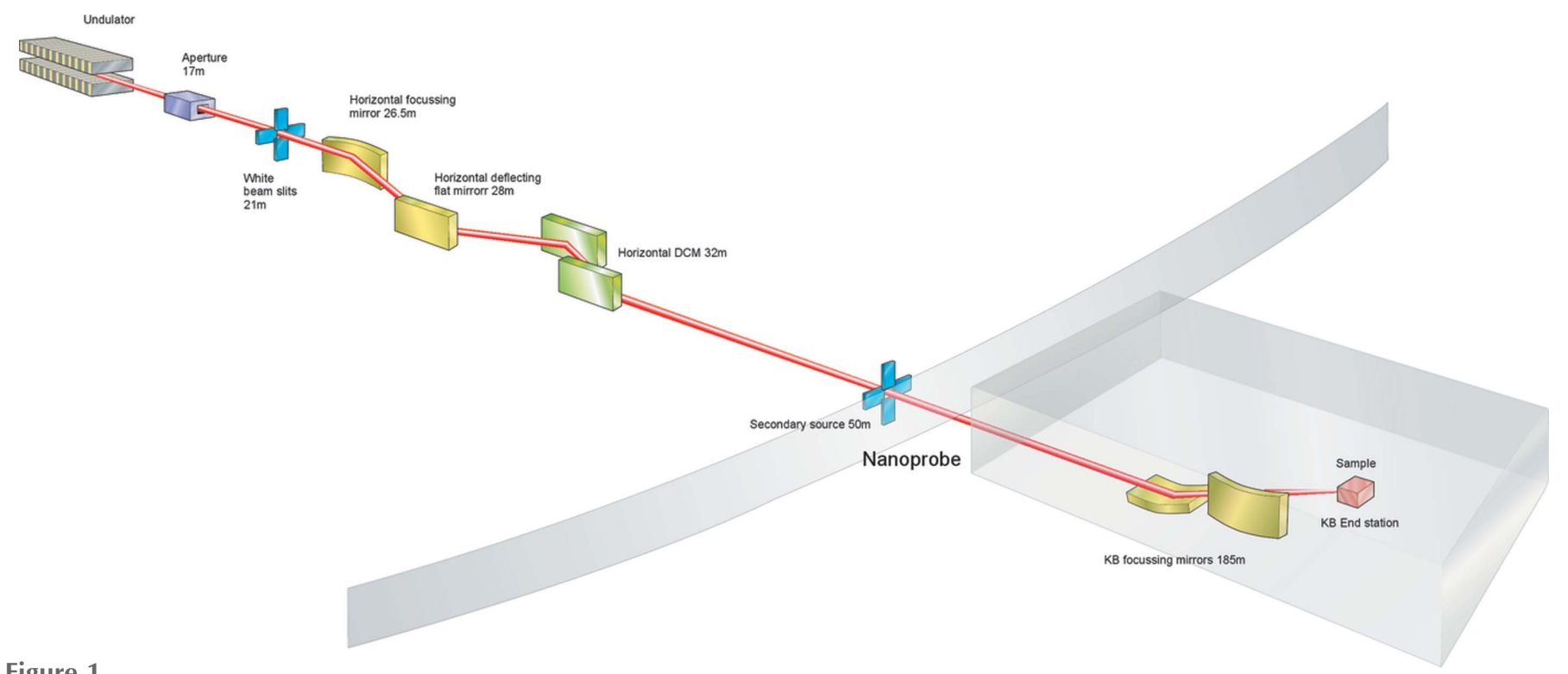

Figure 1

Outline schematic of the Nanoprobe beamline at DLS. 
The beam is first conditioned by two mirrors, used to control the direction of the source and collimate the beam horizontally. The first mirror (M1, white-beam mirror) deflects the photon beam horizontally and collimates the beam in the horizontal direction. The collimation reduces the natural horizontal divergence $\left(\sigma_{\mathrm{h}}^{\prime}\right)$ from $25 \mu \mathrm{rad}$ to approximately $5 \mu \mathrm{rad}$. The second mirror (M2, pink-beam mirror) also deflects the beam horizontally but is flat and is used primarily to control harmonic content as well as both the overall beam direction and the fine control. The mirrors have three coating stripes, $\mathrm{Si}, \mathrm{Rh}$ and $\mathrm{Pt}$, to reduce harmonic contributions across the energy range with both mirrors indirectly water-cooled via a gallium-indium eutectic scheme, employing a gravity fed water-cooling system to minimize vibration.

A horizontal double-crystal monochromator is positioned immediately after the mirrors. The monochromator uses cryogenically cooled $\mathrm{Si}(111)$ crystals and can cover a 4.5$25 \mathrm{keV}$ energy range, although the accessible energy range for experiments is reduced to $5-23 \mathrm{keV}$ due the choice of surface coatings and operating angles on the final $\mathrm{KB}$ focusing mirrors.

The design of mirror M1 allows us to collimate or focus the source 1:1 onto the secondary source aperture. For the source parameters and optical setup of the Nanoprobe, the differences between these schemes were relatively small. The increased beam size and lower divergence of the collimation scheme produced similar flux at the sample compared with the larger divergence of the focusing scheme. Wavefront propagation and optical simulations of heat bumps and their effect on focusing also indicated that the collimation scheme was more robust. Since collimation also has advantages for monochromatic performance, this scheme was chosen as the default operating mode.

The optics are installed within two hutches inside the main synchrotron building with the first optics hutch containing the mirrors and monochromator and the second optics hutch, located at around $50 \mathrm{~m}$ from the source, containing a set of precision slits to define the secondary source. A summary of the optical components and their positions is presented in Table 1.

\subsection{Beam duct and external building}

The beam propagates from the synchrotron to the I14 experiment hutch, which is housed in a purpose-built building also housing the complementary Electron Bio-Imaging Centre (eBIC) and Electron Microscopy centre for physical sciences (ePSIC) (Clare et al., 2017).

The beam duct connecting the synchrotron and external building is constructed of standard concrete with a nominal thickness of $350 \mathrm{~mm}$. Removable concrete lids weighing in excess of 10 tonnes allow access and secured shielding when in place. The beam pipe needs to pass under two sections of road which could not be classed as shielding so additional radiation shielding is provided by a lead 'cloche' style arrangement over the pipes under these sections. The duct, when all lids are in place, is completely enclosed with no access so electrical and
Table 1

Summary of the key components at I14.

\begin{tabular}{|c|c|c|c|}
\hline Component & $\begin{array}{l}\text { Distance } \\
(\mathrm{m})\end{array}$ & Supplier & $\begin{array}{l}\text { Parameters and } \\
\text { comments }\end{array}$ \\
\hline Primary slits & 21 & IDT & - \\
\hline M1 & 26 & IRELEC & $\begin{array}{c}1 \mathrm{~m} \text {-long, } \mathrm{Si}, \mathrm{Rh}, \mathrm{Pt} \text { stripes } \\
\text { Cooling via } \mathrm{Ga} \text { eutetic }\end{array}$ \\
\hline M2 & 27.5 & IRELEC & $\begin{array}{c}1 \mathrm{~m} \text {-long, } \mathrm{Si}, \mathrm{Rh}, \mathrm{Pt} \text { stripes } \\
\text { Cooling via Ga eutetic }\end{array}$ \\
\hline $\mathrm{DCM}$ & 35 & $\begin{array}{l}\text { IDT horizontally } \\
\text { deflecting } \\
\text { monochromator }\end{array}$ & $\begin{array}{l}\mathrm{Si}(111) 60 \mathrm{~mm} \text { and } \\
200 \mathrm{~mm} \text { crystals }\end{array}$ \\
\hline $\begin{array}{l}\text { Diamond single- } \\
\text { crystal BPM }\end{array}$ & 53 & Cividec & $\begin{array}{l}3 \mathrm{~mm} 50 \mu \mathrm{m} \text { diamond } \\
\text { with Ti anodes }\end{array}$ \\
\hline $\begin{array}{l}\text { Horizontal } \\
\text { secondary } \\
\text { source }\end{array}$ & 55 & IDT & $\begin{array}{l}\text { Flexure parallel opening } \\
\text { mechanism with } \\
\text { cylindrical blades }\end{array}$ \\
\hline Feedback BPM & 183 & $\mathrm{ADC}$ & $\begin{array}{l}\text { Two } 50 \mathrm{~mm} \text { gridded } \\
\text { split ion chambers }\end{array}$ \\
\hline Beam defining slits & 183.5 & JJ slits & Scatterless GaAs blades \\
\hline Nano KB & 184 & $\begin{array}{l}\text { JTEC mirrors } \\
\text { /in-house } \\
\text { mechanics }\end{array}$ & $\begin{array}{l}180 \mathrm{~mm}(\mathrm{~V}) \text { and } \\
60 \mathrm{~mm}(\mathrm{H}) \text { long } \\
\text { with } \mathrm{Pt} / \mathrm{Rh} \text { bilayer }\end{array}$ \\
\hline XRF detector & - & Rayspec & $\begin{array}{l}\text { Four } 50 \mathrm{~mm}^{2} \text { Ketek } \\
\text { SDDs with cube } \\
\text { preamplifiers. }\end{array}$ \\
\hline Sample stage & - & $\begin{array}{l}\text { Piezosystem } \\
\text { Jena/Physike } \\
\text { Instrumente } \\
\text { /Attocube }\end{array}$ & 1 \\
\hline Detector table & 185-188 & In house & - \\
\hline
\end{tabular}

vacuum equipment were minimized with no pumps installed within the duct, although three sets of double vacuum gauges monitor the vacuum within the beam pipe. This arrangement provides robustness in vacuum monitoring through redundancy while decreasing the need for unplanned access. This vacuum pipe reaches pressures in the region of $3 \times 10^{-9} \mathrm{mbar}$ at the middle point, despite the pump stations being located at a distance around $113 \mathrm{~m}$ at each end.

The structure of the beamline and electron microscope laboratory floors in the external building echoes that of the Diamond storage ring, consisting of an $800 \mathrm{~mm}$-thick slab supported by $14 \mathrm{~m}$-deep piles. This construction design ensures that seasonal changes due to the water table on the chalk ground are similar on both buildings, minimizing the relative displacement between the source and the endstation in the experimental hutch (Fig. 2).

As depicted in Fig. 2, the 300 mm-thick walls of the hutch are made of reinforced concrete and rest on their own foundations, which are independent of the piles and the rest of the building. There is a $50 \mathrm{~mm}$ gap between the beamline floor and the walls, and between the walls and the building floor. Concrete is very well suited as a construction material for high-stability environments due to its low thermal conductivity and good vibration damping properties. At I14, the thick hutch walls and ceiling provide uniform thermal insulation, structural support for all installations including a $2 \mathrm{~T}$ crane and radiation shielding in the photon energy range of the beamline (up to $23 \mathrm{keV}$ ).

Excellent thermal management is required to maintain stability. The beamline employs a novel radiant panel cooling 




Radiant panels

Hutch walls and roof

Floor slab and piling

Figure 2

Schematic representation of the main structural features of the hutches in the satellite building. The $800 \mathrm{~mm}$ floor slab is supported on piles, buried $14 \mathrm{~m}$ deep into the ground with an air gap around the structure. The $300 \mathrm{~mm}$-thick walls are made of reinforced concrete and rest on their own foundations with a $50 \mathrm{~mm}$ gap between the hutch floor and the wall, and also between the wall and the building floor.

system mounted on the ceilings and walls to remove shortterm thermal oscillations and limit air pressure fluctuations, while avoiding potential issues with high-volume forced air temperature control. To further aid thermal stability, the experimental hutch is accessed via a vestibule with a selfclosing door to minimize the volume of air exchange when opening the hutch door (Cacho-Nerin et al., 2020).

\subsection{Beam positioning}

Whilst an arrangement with all-horizontal optics assists with managing vibrations with respect to beam coherence or focusing, it can pose some challenges for long-term stability and operation. In particular, this arrangement results in a coupling of multiple optical elements to the horizontal beam position and, to a lesser extent, the flux. At many beamlines the beam position is used as an indicator of monochromator alignment and is controlled using the monochromator crystal piezo actuators. This scheme would compensate for drift in the pitch of the mirrors before the monochromator; however, both the beam intensity and the energy calibration would be affected, particularly at low angle/high energy. This is unacceptable for a spectroscopy beamline, where both intensity and energy stability are important. Therefore, a softwarebased feedback system was developed to simultaneously maximize the intensity and control the beam position. The beam intensity and position before the $\mathrm{KB}$ mirrors is measured using two gridded split ion chambers. These were selected over a single-crystal beam position monitor (BPM) to avoid artefacts from electrode patterning, and they serve an additional role in providing a system for recording bulk XAS standards for user experiments. The ion chamber BPM is located at $183 \mathrm{~m}$, and while the position resolution is in the order of micrometres, the large lever arm results in sensitivity to nanoradian-level movements from the primary optics. This scheme is thus robust and allows users to arbitrarily set any energy for scanning within the operating range of the beamline.

\section{Experimental endstation}

The endstation vessel contains both the KB system and sample stage assemblies. These elements are placed in separated chambers, with a $1 \mu \mathrm{m}$-thick silicon nitride membrane acting as a window for the beam to pass through the dividing wall. This allows air, inert gas and vacuum operation on the sample side whilst maintaining a constant protective ultra-high vacuum environment for the focusing optics. Although KB systems can be operated in inert atmospheres, great care must be taken to ensure the atmosphere is clean and dry to guarantee long-term mirror quality. Previous experience at DLS with operation using inert atmospheres has been mixed with some microfocus beamlines showing degradation of the focus and build up on the mirrors within 1 year. The vacuum environment operates at $5 \times 10^{-8}$ mbar, achieved using an ion pump, and mitigates the risk of degradation. It also reduces the risk of any potential room temperature or inert gas temperature related drift.

The KB vertical and horizontal mirror lengths use a 3:1 ratio to provide a similar numerical aperture (NA) for imaging or out-of-focus measurements such as projection imaging or near-field ptychography. The ratio also better matches the horizontal and vertical coherence length differences resulting from the optical scheme of the beamline. The mechanics of the KB mirrors were designed in-house and use a flexure scheme for angular adjustment based on high-stability monochromator designs developed at DLS. The KB mechanics allow for pitch adjustment on each mirror and roll adjustment on the vertical mirror to ensure that they are perpendicular. Survey and offline optical metrology were used to initially position the mirrors but there are no translational motions as the long lever arm of the beamline allows the beam position to be moved by hundreds of micrometres at the KB with only microradian-scale movements of the primary optics. A fourelement XRF detector (RaySpec, UK) in a backscatter geometry is located inside the endstation vessel, with each silicon drift detector (SDD) focused at $17 \mathrm{~mm}$ from the sample (Fig. 3). A hole in the detector allows the beam to pass through and is equipped with a mount for installing pinhole apertures to further clean the beam. The overall arrangement results in a working distance of $6 \mathrm{~mm}$ from the front of the detector. The detector pulse processing is performed using 


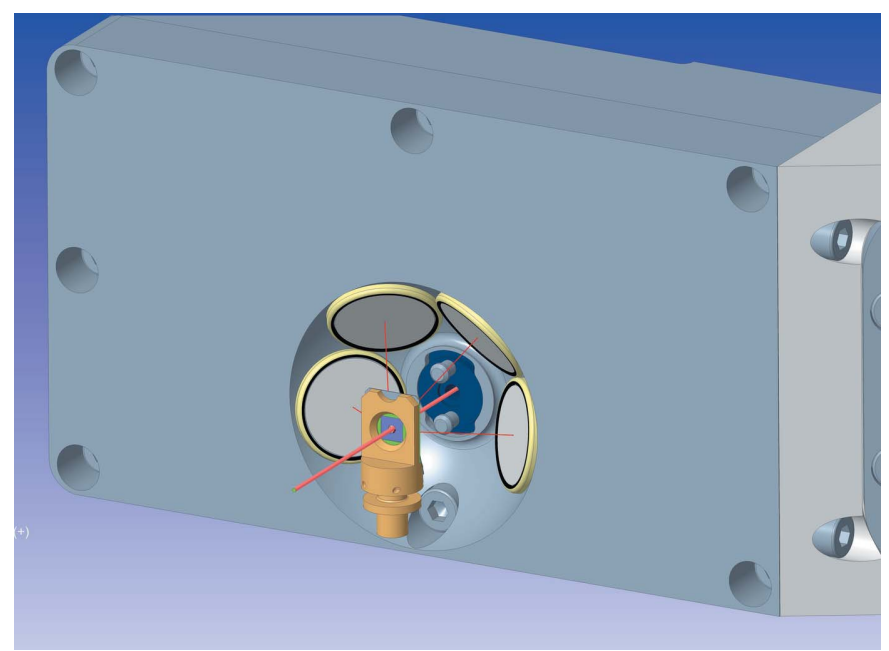

Figure 3

$\mathrm{XRF}$ detector and sample holder arrangement. The sample is $17 \mathrm{~mm}$ from the centre of each sensor. A pinhole mounting is designed into the central aperture of the detector.

Xspress3 (Dennis et al., 2019; Farrow et al., 1995) with an overall maximum count rate of 6 mcps. A backscattering geometry is often not considered optimal due to the increased scatter peak signal; however, the design of in situ sample environments generally restricts the visibility of the sample at $90^{\circ}$ and, in the thin sample regime, the impact of the scatter is acceptable in terms of signal to noise ratio (Sun et al., 2015). An example spectrum, collected at $14 \mathrm{keV}$ from a calibration standard, is shown in Fig. 4.

Several additional detectors are installed downstream of the sample on a granite platform for imaging, diffraction and phase contrast/ptychography applications. Two Medipix3 based detectors (Ballabriga et al., 2011), an Excalibur 3M detector (Marchal et al., 2013) and a Merlin Quad (Quantum Detectors, UK), are mounted adjacent to each other and used for diffraction measurements or phase contrast imaging. Although the detectors are based on the same technology, the



Example XRF spectrum acquired for $1 \mathrm{~s}$ acquisition at $14 \mathrm{keV}$ from a known XRF calibration standard. The backscatter geometry results in a strong elastic and Compton peak in this case, but the excellent peakbackground performance of the detector reduces any impact on dilute concentration measurements. direct beam exposure needed for differential phase contrast (DPC) and ptychography is better managed on a separate smaller detector. For projection imaging, speckle-based imaging and near-field ptychography an effective pixel $<55 \mu \mathrm{m}$ of the Medipix3 is needed, so a scintillator-based detector was built using a sCMOS camera (Andor Neo, Oxford Instruments, Northern Ireland) and a set of standard microscope objectives (Olympus, UK) mounted on a customdesigned rotary stage.

Each of these detectors can be placed between $0.2 \mathrm{~m}$ and $3.5 \mathrm{~m}$ from the sample using independent motorized drives. Motorized lateral motion of the base platform is provided to swap between detector systems in less than $1 \mathrm{~min}$. Each detector also has a compact wedge vertical lift stage, with the scintillator-based camera featuring an additional stage for fine positioning. The general arrangement of the detector platform is shown in Fig. 5.

The sample is mounted on a post and secured by magnets. Positioning is achieved using a mixture of flexure piezo stages and stepper motor controlled cross-roller stages for fine and coarse control, respectively. This combination of piezo and cross-roller stage is commonly used to achieve nano positioning over a long travel range. The cross-roller based stages typically have resonances in the $50-80 \mathrm{~Hz}$ range and the stiffness of the rollers can define the overall stability. For this setup, vibrations at a resonance of $72 \mathrm{~Hz}$ are seen with peaks of $4 \mathrm{~nm}$ vertically and $10 \mathrm{~nm}$ horizontally, respectively. The poorer horizontal performance is in part due to stronger vibrations in this direction from the floor but mainly the stiffness of the overall stack. A calibration chart measured intermittently over a $38 \mathrm{~h}$ period showed maximum drifts of $150 \mathrm{~nm}$ horizontally and $100 \mathrm{~nm}$ vertically, but in practice the authors observed variations in drift which are dependent on the sample and mounting. A compact rotary stage helps to optimize the angular position of flat samples and enables advanced techniques such as multimodal tomography. Locating the sample is achieved by a retractable in-line microscope positioned downstream. This shares the focal

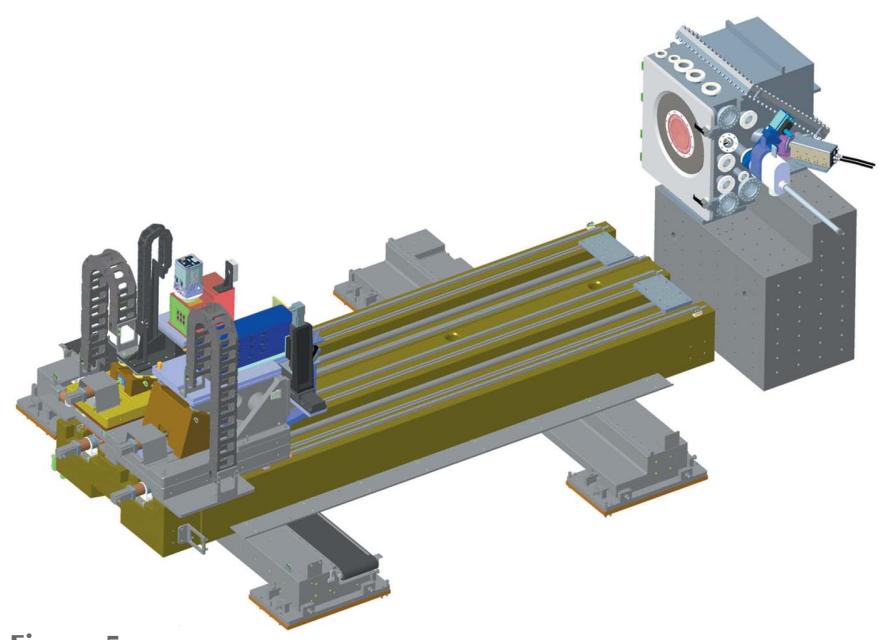

Figure 5

General arrangement of the combined sample/KB vessel and the platform hosting downstream detectors. 
plane with the KB system while offering a smaller depth of focus, guaranteeing that if the sample is in focus in this microscope it is also at the X-ray focus. A focal spot size of $50 \mathrm{~nm}$ is achieved at $12 \mathrm{keV}$, measured using ptychography and resolution targets (Fig. 7). The spot size varies, as expected, due to changes in the diffraction limit across the beamline energy range. Flux on the sample, at $12 \mathrm{keV}$, is approximately $5.4 \times 10^{9}$ photons $^{-1}$ at the finest focus. Opening the secondary source aperture broadens the horizontal spot size and increases flux. A flux of $5 \times 10^{10}$ photons $\mathrm{s}^{-1}$ can be achieved, for example, by increasing to a $250 \mathrm{~nm}$ horizontal beam size.

\section{User operations}

Scanning probe experiments allow for a range of multimodal measurements using different detectors and scan types (e.g. ptychography, XRD, XRF, XANES and tomography), so there is a requirement for flexible scanning of detectors, translations, rotations and energy. The broad range of techniques coupled with the wide variety of science applications and heterogeneous, often novice, user base has led DLS to develop an integrated technology stack which can be deployed across the facility. This provides a flexible and easy to use user interface that allows intuitive interaction with the beamline while abstracting hardware details which are not of immediate interest to the user. The system provides experiment control, hardware-based scanning and triggering, task scheduling, and automated processing for agile feedback during the experiment (Basham et al., 2018). It is also fully scriptable so that complex experiments and new techniques can be implemented quickly.

Verification of the focal spot size and re-focusing of the KB, if required, are performed before each user experimental session using ptychographic reconstruction of the sample or a reference target.

In a typical experiment, once the sample is mounted on the stage, the first operation is to position the sample at the X-ray focus using the in-line microscope and interactive controls for the sample stages to find an area of interest with. A marker in the image indicates the approximate position of the X-ray beam within $\sim 1 \mu \mathrm{m}$. The scan is defined by drawing a region of interest on the captured frame from the camera and selecting either the number of points required or the step size in each direction, as well as whether scanning should be continuous or step by step. After choosing the detector combination and the dwell time the scan can be submitted to the queue which manages the hardware required for data acquisition.

Before launching the scan, the microscope is retracted, and the appropriate detector is moved into place. The complex motion sequence is carried out by a script in order to avoid potential collisions. Prior to submission, the user can optionally define one or more 'processing chains' which run continuously and process detector data as they arrive, providing direct feedback on experiment progress and dynamic data processing and visualization. Typical examples are peak integration to select elements of interest from the $\mathrm{XRF}$ signal, or frame processing for differential phase contrast. Because all data, including the microscope image, share the same coordinate space, data from different sample regions can be overlaid and displayed simultaneously. An intuitive point-and-click interface allows interactive inspection of both raw and processed data of any point in a scan. The online data processing and integrated visualization are key elements of the experiment workflow, since they enable progressive refinement of the scan area. Thus, typically a coarse scan with $500-750 \mathrm{~nm}$ step sizes is launched over a relatively large area, providing a broad overview of the sample at a resolution comparable to the optical microscope. Based on the processed results, the step size can be progressively refined over smaller areas, providing a 'zoom' effect with increasing spatial resolution.

Early beamline publications (McCulloch et al., 2019; Gomez-Gonzalez et al., 2019; Morrell et al., 2019; Walker et al., 2018) highlight some of the XRF, nano-XANES and nanoXRD capabilities. Fig. 6 shows nano-XANES maps acquired on $\mathrm{ZnO}$ nanorods which were incubated in situ in a simulated sludge solution (Gomez-Gonzalez et al., 2019). In this experiment, a spectro-microscopy methodology for speciation analysis was followed, based on multiple 2D XRF maps acquired around and across the $\mathrm{Zn} K$-edge. The XANES data were aligned and processed in a similar fashion to STXM, using PCA and cluster analysis to extract variations in the recorded sample spectra [Fig. 6(c)] (Lerotic et al., 2004, 2014). As a simple example of the ptychography and general imaging capabilities, Fig. 7 shows XRF, DPC and ptychography images


(b)


Figure 6

(a) Spectro-microscopy methodology for speciation analysis, based on acquiring multi-energy 2D fluorescence maps along the absorption edge of the target element. In this experiment 135 energies across the $\mathrm{Zn} K$ edge were scanned. (b) XRF map (Zn K $\alpha$ emission) collected above the $\mathrm{Zn} K$-absorption edge $(E=9,669 \mathrm{eV})$. Scale bar length: $750 \mathrm{~nm}$. The numbering on the colour scale bar represents fluorescence intensity (arbitrary units). (c) Cluster analysis representation revealing statistically similar regions according to their XANES spectra. Image reprinted (adapted) with permission from Gomez-Gonzalez et al. (2019). Copyright 2019 American Chemical Society. 
of a $1 \mu \mathrm{m} \times 1 \mu \mathrm{m}$ area from a tungsten test object with $50 \mathrm{~nm}$ feature spacing.

\section{Conclusions}

We have designed, constructed and commissioned a highresolution versatile scanning microscope suitable for multimodal-imaging in the hard X-ray regime with particular emphasis on energy scanning for XAS-based measurements. The Nanoprobe supports X-ray fluorescence, transmission
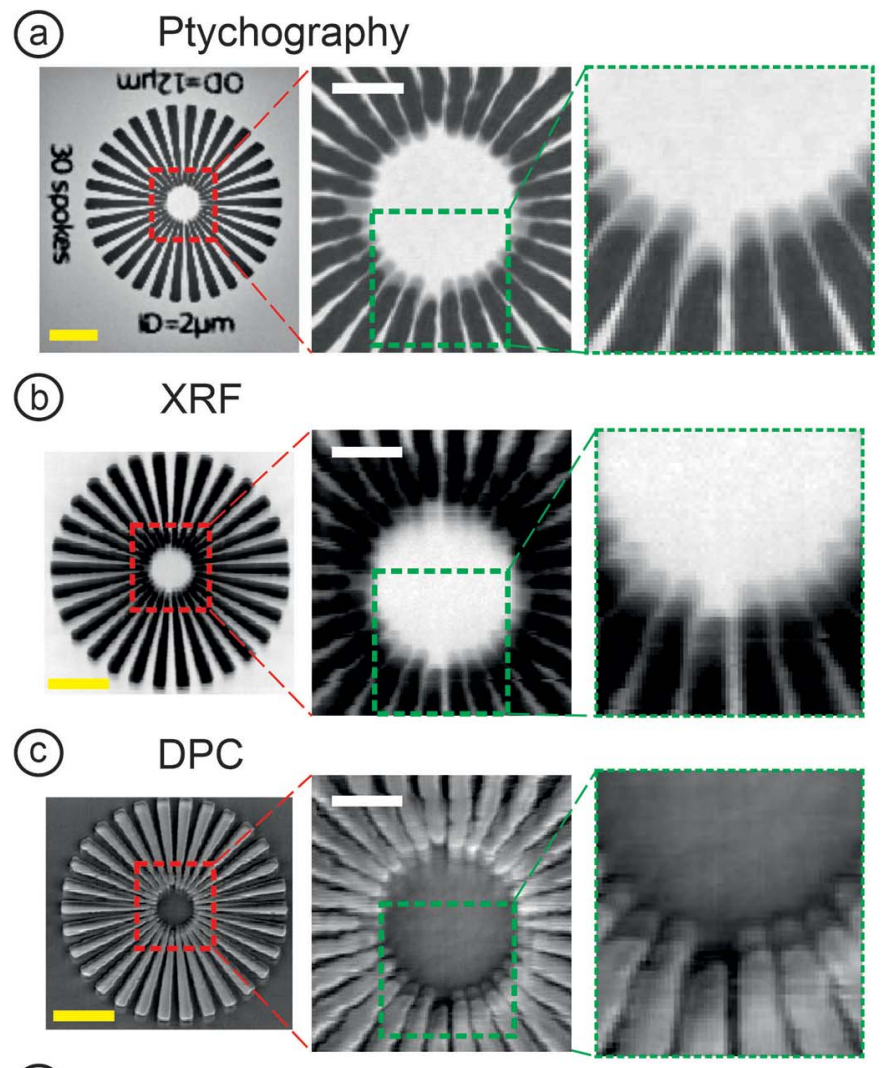

(d)

FWHM [vert. $]=49 \mathrm{~nm}$

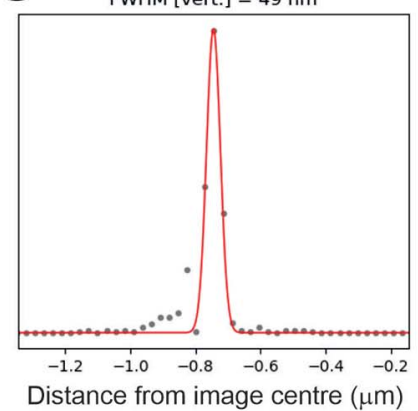

Distance from image centre $(\mu \mathrm{m})$

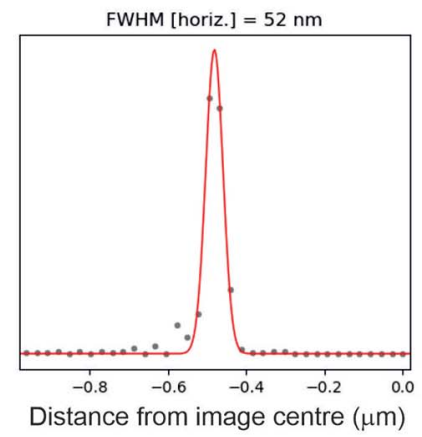

Figure 7

Multimodal imaging of a tungsten Siemens Star with $70 \mathrm{~nm}$ minimum feature size using $(a)$ ptychography, $(b)$ XRF and (c) DPC. (d) A typical beam profile extracted from ptychography reconstructions at $12 \mathrm{keV}$. The ptychography scan was acquired out of focus, covering a $16 \mu \mathrm{m} \times 16 \mu \mathrm{m}$ area. The zoomed-in area shows the detail of the high-resolution features in the reconstruction. XRF ( $L \alpha$ emission) and DPC maps of the Siemens Star were acquired simultaneously at focus with $50 \mathrm{~ms}$ dwell time and $40 \mathrm{~nm}$ scan steps per pixel. Scale bars in all pictures are $1 \mu \mathrm{m}$. The pixel size in the ptychographic reconstructions is $27 \mathrm{~nm}$. diffraction, differential phase contrast, ptychography and tomography imaging techniques with a nominal beam size of $50 \mathrm{~nm} \times 50 \mathrm{~nm}$ allowing I14 to tackle problems in a diverse range of scientific areas such as life, geological, environmental and materials sciences. The instrument is operational and open to the general user community.

\section{Acknowledgements}

The authors would like to thank Chris Binns for leading the inception of the Nanoprobe beamline project. The authors are grateful for the continued assistance and collaboration of the various Diamond support groups. In particular we would like to thank Ed Warrick and Anthony Hull for hardware controls and data acquisition development; and Kevin Collins, Mark Hooper and Ljubo Zaja for their work on the engineering design. We would also like to thank Darren Batey and Benedikt Daurer for their assistance with ptychography experiments and implementation on the beamline.

\section{References}

Ballabriga, R., Campbell, M., Heijne, E., Llopart, X., Tlustos, L. \& Wong, W. (2011). Nucl. Instrum. Methods Phys. Res. A, 633, S15S18.

Basham, M., Filik, J., Cobb, T., Mudd, J. J., Mosselmans, J. F. W., Dudin, P., Parsons, A. D., Quinn, P. D. \& Dent, A. J. (2018). Synchrotron Radiat. News. 31(5), 21-26.

Cacho-Nerin, F., Parker, J. E. \& Quinn, P. D. (2020). J. Synchrotron Rad. 27, 912-922.

Chang, S. H., Yin, G. C., Wang, D. J., Chang, C. H., Juang, J. M., Huang, L. J., Liu, C. Y., Chang, C. F., Chu, C. H. \& Tang, M. T. (2013). J. Phys. Conf. Ser. 425, 182005.

Chen, S., Deng, J., Yuan, Y., Flachenecker, C., Mak, R., Hornberger, B., Jin, Q., Shu, D., Lai, B., Maser, J., Roehrig, C., Paunesku, T., Gleber, S. C., Vine, D. J., Finney, L., VonOsinski, J., Bolbat, M., Spink, I., Chen, Z., Steele, J., Trapp, D., Irwin, J., Feser, M., Snyder, E., Brister, K., Jacobsen, C., Woloschak, G. \& Vogt, S. (2014). J. Synchrotron Rad. 21, 66-75.

Clare, D. K., Siebert, C. A., Hecksel, C., Hagen, C., Mordhorst, V., Grange, M., Ashton, A. W., Walsh, M. A., Grünewald, K., Saibil, H. R., Stuart, D. I. \& Zhang, P. (2017). Acta Cryst. D73, 488-495.

Cotte, M., Genty-Vincent, A., Janssens, K. \& Susini, J. (2018). C. R. Phys. 19, 575-588.

Deng, J., Lo, Y. H., Gallagher-Jones, M., Chen, S., Pryor, A., Jin, Q., Hong, Y. P., Nashed, Y. S. G., Vogt, S., Miao, J. \& Jacobsen, C. (2018). Sci. Adv. 4, 1-11.

Deng, J., Preissner, C., Klug, J. A., Mashrafi, S., Roehrig, C., Jiang, Y., Yao, Y., Wojcik, M., Wyman, M. D., Vine, D., Yue, K., Chen, S., Mooney, T., Wang, M., Feng, Z., Jin, D., Cai, Z., Lai, B. \& Vogt, S. (2019). Rev. Sci. Instrum. 90, 083701.

Dennis, G., Helsby, W., Omar, D., Horswell, I., Tartoni, N., Hayama, S., Mikulska, I. \& Diaz-Moreno, S. (2019). AIP Conf. Proc. 2054, 060065 .

Farrow, R. E., Derbyshire, G., Dobson, B., Dent, A. J., Bogg, D., Headspith, J., Lawton, R., Martini, M., Trammell, R. \& Buxton, K. (1995). Rev. Sci. Instrum. 66, 2307-2309.

Gomez-Gonzalez, M. A., Koronfel, M. A., Goode, A. E., Al-Ejji, M., Voulvoulis, N., Parker, J. E., Quinn, P. D., Scott, T. B., Xie, F., Yallop, M. L., Porter, A. E. \& Ryan, M. P. (2019). ACS Nano. 13, 11049-11061.

Hémonnot, C. Y. J. \& Köster, S. (2017). ACS Nano. 11, 8542-8559.

Holler, M., Raabe, J., Diaz, A., Guizar-Sicairos, M., Wepf, R., Odstrcil, M., Shaik, F. R., Panneels, V., Menzel, A., Sarafimov, B., 
Maag, S., Wang, X., Thominet, V., Walther, H., Lachat, T., Vitins, M. \& Bunk, O. (2018). Rev. Sci. Instrum. 89, 043706.

Huang, X., Yan, H., Nazaretski, E., Conley, R., Bouet, N., Zhou, J., Lauer, K., Li, L., Eom, D., Legnini, D., Harder, R., Robinson, I. K. \& Chu, Y. S. (2013). Sci. Rep. 3, 3562.

Johannes, A., Salomon, D., Martinez-Criado, G., Glaser, M., Lugstein, A. \& Ronning, C. (2017). Sci. Adv. 3, eaao4044.

Johansson, U., Vogt, U. \& Mikkelsen, A. (2013). Proc. SPIE, 8851, $88510 \mathrm{~L}$.

Jonge, M. D. de, Ryan, C. G. \& Jacobsen, C. J. (2014). J. Synchrotron Rad. 21, 1031-1047.

Krüger, S. P., Neubauer, H., Bartels, M., Kalbfleisch, S., Giewekemeyer, K., Wilbrandt, P. J., Sprung, M. \& Salditt, T. (2012). J. Synchrotron Rad. 19, 227-236.

Lerotic, M., Jacobsen, C., Schäfer, T. \& Vogt, S. (2004). Ultramicroscopy, 100, 35-57.

Lerotic, M., Mak, R., Wirick, S., Meirer, F. \& Jacobsen, C. (2014). J. Synchrotron Rad. 21, 1206-1212.

Liu, L., Milas, N., Mukai, A. H. C., Resende, X. R. \& de Sá, F. H. (2014). J. Synchrotron Rad. 21, 904-911.

Marchal, J., Horswell, I., Willis, B., Plackett, R., Gimenez, E. N., Spiers, J., Ballard, D., Booker, P., Thompson, J. A., Gibbons, P., Burge, S. R., Nicholls, T., Lipp, J. \& Tartoni, N. (2013). J. Phys. Conf. Ser. 425, 062003.

Martínez-Criado, G., Villanova, J., Tucoulou, R., Salomon, D., Suuronen, J.-P., Labouré, S., Guilloud, C., Valls, V., Barrett, R., Gagliardini, E., Dabin, Y., Baker, R., Bohic, S., Cohen, C. \& Morse, J. (2016). J. Synchrotron Rad. 23, 344-352.

McCulloch, A., Bennie, L., Coulter, J. A., McCarthy, H. O., Dromey, B., Grimes, D. R., Quinn, P., Villagomez-Bernabe, B. \& Currell, F. (2019). Part. Part. Syst. Charact. 36, 1900140.

Mimura, H., Handa, S., Kimura, T., Yumoto, H., Yamakawa, D., Yokoyama, H., Matsuyama, S., Inagaki, K., Yamamura, K., Sano, Y., Tamasaku, K., Nishino, Y., Yabashi, M., Ishikawa, T. \& Yamauchi, K. (2010). Nat. Phys. 6, 122-125.

Mohacsi, I., Vartiainen, I., Rösner, B., Guizar-Sicairos, M., Guzenko, V. A., McNulty, I., Winarski, R., Holt, M. V. \& David, C. (2017). Sci. Rep. 7, 1-10.

Morrell, A. P., Floyd, H. W., Mosselmans, J. F., Grover, L. M., CastilloMichel, H., Davis, E. T., Parker, J. E., Martin, R. A. \& Addison, O. (2019). Acta Biomaterialia, 98, 284-293.

Nazaretski, E., Huang, X., Yan, H., Lauer, K., Conley, R., Bouet, N., Zhou, J., Xu, W., Eom, D., Legnini, D., Harder, R., Lin, C. H., Chen, Y. S., Hwu, Y. \& Chu, Y. S. (2014). Rev. Sci. Instrum. 85, 033707.

Nazaretski, E., Yan, H., Lauer, K., Bouet, N., Huang, X., Xu, W., Zhou, J., Shu, D., Hwu, Y. \& Chu, Y. S. (2017). J. Synchrotron Rad. 24, 1113-1119.

Patommel, J., Klare, S., Hoppe, R., Ritter, S., Samberg, D., Wittwer, F., Jahn, A., Richter, K., Wenzel, C., Bartha, J. W., Scholz, M., Seiboth,
F., Boesenberg, U., Falkenberg, G. \& Schroer, C. G. (2017). Appl. Phys. Lett. 110, 101103.

Schroer, C. G., Boye, P., Feldkamp, J. M., Patommel, J., Samberg, D., Schropp, A., Schwab, A., Stephan, S., Falkenberg, G., Wellenreuther, G. \& Reimers, N. (2010). Nucl. Instrum. Methods Phys. Res. A, 616, 93-97.

Schroer, C. G., Seyrich, M., Kahnt, M., Botta, S., Döhrmann, R., Falkenberg, G., Garrevoet, J., Lyubomirskiy, M., Scholz, M., Schropp, A. \& Wittwer, F. (2017). Proc. SPIE, 13, 103890E.

Seiboth, F., Schropp, A., Scholz, M., Wittwer, F., Rödel, C., Wünsche, M., Ullsperger, T., Nolte, S., Rahomäki, J., Parfeniukas, K., Giakoumidis, S., Vogt, U., Wagner, U., Rau, C., Boesenberg, U., Garrevoet, J., Falkenberg, G., Galtier, E. C., Ja Lee, H., Nagler, B. \& Schroer, C. G. (2017). Nat. Commun. 8, 14623.

Somogyi, A., Medjoubi, K., Baranton, G., Le Roux, V., Ribbens, M., Polack, F., Philippot, P. \& Samama, J.-P. (2015). J. Synchrotron Rad. 22, 1118-1129.

Sun, Y., Gleber, S. C., Jacobsen, C., Kirz, J. \& Vogt, S. (2015). Ultramicroscopy, 152, 44-56.

Suzuki, M., Kawamura, N., Mizumaki, M., Terada, Y., Uruga, T., Fujiwara, A., Yamazaki, H., Yumoto, H., Koyama, T., Senba, Y., Takeuchi, T., Ohashi, H., Nariyama, N., Takeshita, K., Kimura, H., Matsushita, T., Furukawa, Y., Ohata, T., Kondo, Y., Ariake, J., Richter, J., Fons, P., Sekizawa, O., Ishiguro, N., Tada, M., Goto, S., Yamamoto, M., Takata, M. \& Ishikawa, T. (2013). J. Phys. Conf. Ser. 430, 012017.

Suzuki, Y., Takeuchi, A., Takenaka, H. \& Okada, I. (2010). X-ray Opt. Instrum. 2010, 824387.

Tavares, P. F., Leemann, S. C., Sjöström, M. \& Andersson, Å. (2014). J. Synchrotron Rad. 21, 862-877.

Tolentino, H. C. N., Soares, M. M., Perez, C. A., Vicentin, F. C., Abdala, D. B., Galante, D., Teixeira, V. D. C., De Araujo, D. H. C. \& Westfahl, H. (2017). J. Phys. Conf. Ser. 849, 012057.

Walker, M., Howes, P., McNutt, P., Harvey, D., Dong, H., CachoNerin, F. \& Quinn, P. (2018). Proceedings from the International Thermal Spray Conference 7-10 May 2018, Orlando, Florida, USA, pp. 248-255. ASM International.

Winarski, R. P., Holt, M. V., Rose, V., Fuesz, P., Carbaugh, D., Benson, C., Shu, D., Kline, D., Stephenson, G. B., McNulty, I. \& Maser, J. (2012). J. Synchrotron Rad. 19, 1056-1060.

Yamauchi, K., Mimura, H., Kimura, T., Yumoto, H., Handa, S., Matsuyama, S., Arima, K., Sano, Y., Yamamura, K., Inagaki, K., Nakamori, H., Kim, J., Tamasaku, K., Nishino, Y., Yabashi, M. \& Ishikawa, T. (2011). J. Phys. Condens. Matter, 23, 394206.

Yu, Y. S., Farmand, M., Kim, C., Liu, Y., Grey, C. P., Strobridge, F. C., Tyliszczak, T., Celestre, R., Denes, P., Joseph, J., Krishnan, H., Maia, F. R. N. C., Kilcoyne, A. L. D., Marchesini, S., Leite, T. P. C., Warwick, T., Padmore, H., Cabana, J. \& Shapiro, D. A. (2018). Nat. Commun. 9, 921. 